\title{
Treatment of trigeminal neuralgia: role of radiofrequency ablation
}

\author{
Dessy R Emril' \\ Kok-Yuen $\mathrm{Ho}^{2}$ \\ 'Neurology Department, Syiah \\ Kuala University/Dr Zainoel Abidin \\ Hospital, Banda Aceh, Indonesia; \\ ${ }^{2}$ Pain Management Centre, \\ Raffles Hospital, Singapore
}

This article was published in the following Dove Press journal: Journal of Pain Research

10 December 2010

Number of times this article has been viewed

\begin{abstract}
Trigeminal neuralgia $(\mathrm{TN})$ is a neuropathic pain condition affecting the face. It has a significant impact on the quality of life and physical function of patients. Evidence suggests that the likely etiology is vascular compression of the trigeminal nerve leading to focal demyelination and aberrant neural discharge. Secondary causes such as multiple sclerosis or brain tumors can also produce symptomatic TN. Treatment must be individualized to each patient. Carbamazepine remains the drug of choice in the first-line treatment of TN. Minimally invasive interventional pain therapies and surgery are possible options when drug therapy fails. Younger patients may benefit from microvascular decompression. Elderly patients with poor surgical risk may be more suitable for percutaneous trigeminal nerve rhizolysis. The technique of radiofrequency rhizolysis of the trigeminal nerve is described in detail in this review.
\end{abstract}

Keywords: interventional treatment, minimally invasive, pain management, radiofrequency rhizolysis, trigeminal neuralgia

\section{Introduction}

Trigeminal neuralgia (TN) is a painful condition involving the face. It is the most frequently diagnosed form of facial pain with a prevalence of 4 per 100,000 in the general population. ${ }^{1}$ It commonly affects patients aged over 50 years and occurs more frequently in women than men with a ratio of $1.5: 1$ to $2: 1$, respectively. ${ }^{1}$ It is also more common in patients with multiple sclerosis (incidence of $1 \%-2 \%$ ) and hypertension. ${ }^{1} \mathrm{TN}$ is associated with decreased quality of life and impairment of daily function. It impacts upon employment in $34 \%$ of patients, and depressive symptoms are not uncommon. ${ }^{2,3}$ The condition may be severely disabling with high morbidity, particularly in the elderly. ${ }^{4}$

\section{Pathophysiology}

The pathophysiology of TN remains unclear. Evidence suggests that pain occurs because of pressure on the trigeminal nerve root at the entry zone into the pontine region of the brain stem. ${ }^{4,5}$ Compression by tumor or blood vessel may cause local pressure, leading to demyelination of the trigeminal nerve. Results from experimental studies suggest that demyelinated axons are prone to ectopic action potential generation. ${ }^{4,6}$ Demyelination has also been shown in cases of TN associated with multiple sclerosis and tumor compression of the trigeminal nerve root.

\section{Diagnosis}

TN is characterized by sharp, shooting, 'electric shock-like' pain sensation that is limited to one or more branches of the trigeminal nerve. It is almost always unilateral 
with the maxillary branch being most commonly affected and the ophthalmic branch the least. ${ }^{1}$ Pain usually lasts from a few seconds to 2 min and may recur spontaneously between pain-free intervals. Most patients report a sensitive trigger zone that reproduces an attack of neuralgia if lightly touched. Routine daily activities that contact, mobilize, stretch, or even slightly stimulate the trigger zone, such as brushing the teeth, applying facial cosmetics, encountering a breeze, talking, or eating, may trigger intolerable pain.

The International Headache Society has published criteria for the diagnosis of classical or symptomatic TN (Table 1). ${ }^{7}$ In classical $\mathrm{TN}$, no etiology can be identified other than vascular compression. On the other hand, symptomatic TN is related to an underlying cause such as tumor compression or multiple sclerosis. It is therefore important to distinguish between the two as the focus in management of symptomatic $\mathrm{TN}$ is to treat the underlying cause.

Another useful classification that is commonly used may be more relevant to clinicians: 8,9

1. TN1 - idiopathic, spontaneous facial pain that is predominantly episodic;

2. TN2 - idiopathic, spontaneous facial pain that is predominantly constant;

3. Trigeminal neuropathic pain resulting from unintentional injury to the trigeminal nerve due to trauma or surgery;

4. Trigeminal deafferentation pain resulting from intentional injury to the nerve by peripheral nerve ablation,

Table I International Headache Society diagnostic criteria for trigeminal neuralgia

Classical
A. Paroxysmal attacks of pain lasting from a fraction of a second to
2 min, affecting one or more divisions of the trigeminal nerve, and
fulfilling criteria B and C
B. Pain has at least one of the following characteristics:
I. Intense, sharp, superficial, or stabbing
2. Precipitated from trigger zones or by trigger factors
C. Attacks are sterotyped in the individual patient
D. There is no clinically evident neurologic deficit
E. Not attributed to another disorder
Symptomatic
A. Paroxysmal attacks of pain lasting from a fraction of a second to
2 min, with or without persistence of aching between paroxysms,
affecting one or more divisions of the trigeminal nerve, and fulfilling
criteria B and C
B. Pain has at least one of the following characteristics:
I. Intense, sharp, superficial, or stabbing
2 . Precipitated from trigger zones or by trigger factors
C. Attacks are sterotyped in the individual patient
D. A causative lesion, other than vascular compression, has been
demonstrated by special investigations and/or posterior fossa
exploration

gangliolysis, or rhizotomy in an attempt to treat either TN or other related facial pain;

5. Symptomatic TN due to multiple sclerosis;

6. Post-herpetic TN following a cutaneous herpes zoster outbreak in the trigeminal distribution; and

7. Atypical facial pain that refers to facial pain secondary to a somatoform pain disorder and requires psychological testing for diagnostic confirmation.

Many TN patients may also manifest a combination of TN1 and TN2 characteristics, together or at separate times during the natural course of the disease. For example, a patient may have a dull, nearly constant background pain in between paroxysmal attacks of sharp or electrical shock-like pain.

Neurological examination is usually normal in patients with idiopathic $\mathrm{TN}$, although a subtle trigeminal sensory deficit may be detected occasionally. ${ }^{10}$ However, symptoms of TN may also be the first manifestation in patients with cerebellopontine angle tumors or multiple sclerosis. Therefore, patients should be asked about other neurologic symptoms such as tingling, numbness, loss of balance, weakness in one or more limbs, blurred or double vision, hearing loss, dizziness, headaches, and fits.

Magnetic resonance imaging (MRI) scan of the brain is useful to exclude symptomatic TN due to multiple sclerosis and tumors. MRI sequences augmented by a three-dimensional gradient echo sequence such as fast inflow with steady-state precession or intravenous gadolinium-DTPA can also improve visualization of the vascular compression around the trigeminal nerve root. ${ }^{11}$

Differential diagnoses for facial pain include headache disorders, temporomandibular joint pain, dental pain, chronic sinusitis, otitis media, as well as myofascial pain. A discussion of these conditions is beyond the scope of this review. In general, the facial location, sharp or electrical quality, excruciating intensity, phasic temporal profile, and responsiveness to a specific drug can help us distinguish TN from other types of facial pain. ${ }^{10}$

\section{Treatment}

The treatment of patients with idiopathic TN is often a challenge in clinical practice, and conservative management with drug therapy is always the first-line treatment. When drugs are not efficacious or produce intolerable adverse effects, interventional pain treatment or surgery is the possible option.

\section{Pharmacological treatment}

Carbamazepine has been used for many decades in the treatment of TN, and it is the drug of choice. ${ }^{12,13}$ Meta-analyses 
have demonstrated the efficacy of carbamazepine with a number-needed-to-treat of 2.5. ${ }^{13,14}$ Carbamazepine may even have diagnostic utility because patients with classical TN will respond well to it. Patients with symptomatic TN or other causes of facial pain are less likely to respond to carbamazepine. Doses of carbamazepine range between 200 and $1200 \mathrm{mg}$ daily.

Other medications with reported efficacy in TN include oxcarbazepine, baclofen, and lamotrigine. ${ }^{15-17}$ Other medications such as topiramate, gabapentin, pregabalin, and levetiracetam have shown success in treating TN, but evidence is limited to small uncontrolled studies or case reports. ${ }^{15}$ Patients should receive an adequate trial of at least three drugs including carbamazepine before surgical or interventional treatment is considered. ${ }^{10}$

\section{Surgical treatment}

Microvascular decompression (MVD) and gamma knife surgery (GKS) are surgical options available to patients with TN.

\section{Surgical MVD}

MVD has been widely used based on the theory that vascular compression of the trigeminal nerve is responsible for TN. ${ }^{18,19}$ Craniotomy is performed to separate the blood vessels from the trigeminal nerve using an inert sponge or felt. ${ }^{20} \mathrm{~A}$ recent retrospective review of patients with TN who had undergone MVD showed that a high proportion of patients (71\%) reported complete pain relief 10 years after surgery. ${ }^{21}$

Mortality rate for MVD ranges from $0.2 \%$ to $0.5 \%$. There is a $4 \%$ incidence of postoperative morbidity such as cerebrospinal fluid (CSF) leak, infarct, or hematoma formation. ${ }^{21}$

\section{Ablative techniques}

\section{Gamma knife surgery}

GKS is a noninvasive stereotactic radiosurgical technique that utilizes a focused beam of radiation to target the root of the trigeminal nerve. It is commonly performed with the patient under sedation. Pain relief obtained from GKS is delayed and usually occurs about 2 weeks later. Initial good pain relief can be achieved in $\sim 80 \%$ of patients. ${ }^{22,23}$ However, there is a risk of recurrence after 1 year. ${ }^{22}$ GKS may be preferred to MVD in elderly patients because of the lower rate of surgical complications. ${ }^{24}$ Complications include facial paresthesia, hypoesthesia, and sensory loss. Anesthesia dolorosa has not been reported. ${ }^{15}$

Minimally invasive percutaneous techniques for treating TN include balloon compression, glycerol rhizolysis, and radiofrequency $(\mathrm{RF})$ rhizotomy.

\section{Balloon compression}

In balloon compression, a small balloon is introduced percutaneously using a needle to compress the trigeminal ganglion. Pain relief was immediate in more than $80 \%$ of patients. ${ }^{25,26}$ Complications include severe bradycardia or asystole, corneal anesthesia, facial sensory loss or dysesthesia, and masseter weakness. ${ }^{25}$ In a 20-year follow-up review, recurrence of pain occurred in $32 \%$ of patients over the entire study period. ${ }^{26}$

\section{Glycerol rhizolysis}

This procedure is performed with the patient in the sitting position with the head flexed. A needle is introduced into the trigeminal cistern and glycerol is injected. As glycerol is hyperbaric, it will sink and produce discrete neurolytic lesions of the second and third divisions of the trigeminal nerve. Pain relief has been reported to be more than $90 \%$ in one study with a recurrence rate of $23 \%$ after a mean period of 30 months. ${ }^{27}$

\section{Radiofrequency rhizotomy}

This review will focus on the role of RF rhizotomy in the treatment of TN. Patients with TN who have good to excellent pain relief with a diagnostic trigeminal ganglion block may be suitable candidates for percutaneous RF rhizotomy, especially if the pain relief is of a short duration. It is performed by destruction of the trigeminal ganglion or roots using RF.

$\mathrm{RF}$ is the most common percutaneous procedure used to treat $\mathrm{TN}$, especially in elderly patients.

\section{Procedure}

Patients are fasted for at least $6 \mathrm{~h}$ before the procedure. Prophylactic antibiotic is administered $1 \mathrm{~h}$ before the procedure. Intravenous access is obtained, and standard monitors including electrocardiogram, blood pressure monitoring, and pulse oximetry are applied. Sedation is usually necessary to increase patient comfort and reduce anxiety.

The procedure is performed under fluoroscopic guidance with the patient in the supine position and head extended. The $\mathrm{C}$-arm is rotated to obtain an oblique submental view to visualize the foramen ovale. The skin entry point is $\sim 2-3 \mathrm{~cm}$ lateral to the commissura labialis (angle of the mouth) on the affected side. The needle trajectory follows a straight line directed toward the pupil when seen from the front and passes $3 \mathrm{~cm}$ anterior to the external auditory meatus when seen from the side. ${ }^{28}$

A 22-gauge, 10-cm RF cannula with a 5-mm active tip is used. After administration of local anesthesia, the cannula is advanced in a coaxial manner (tunnel view) to the X-ray beam toward the foramen ovale (Figure 1). A finger can be 


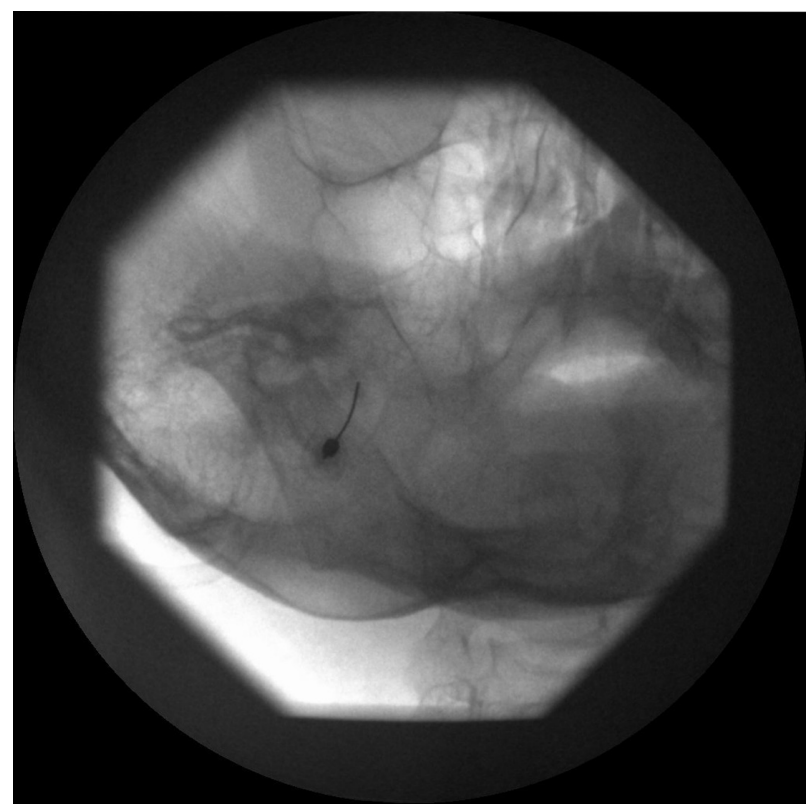

Figure I Left oblique submental fluoroscopic view showing needle directed toward the foramen ovale.

placed in the oral cavity to make sure that the buccal mucosa has not been perforated. When the cannula enters the foramen ovale, the depth of the cannula inside the Meckel's cavity is ascertained on the lateral fluoroscopic view. The electrode is advanced 2-4 $\mathrm{mm}$ further through the canal of the foramen ovale such that the tip of the electrode reaches the junction of the petrous ridge of the temporal bone and the clivus (Figure 2). The stylet is then removed from the cannula, and aspiration is performed to ensure that there is no CSF

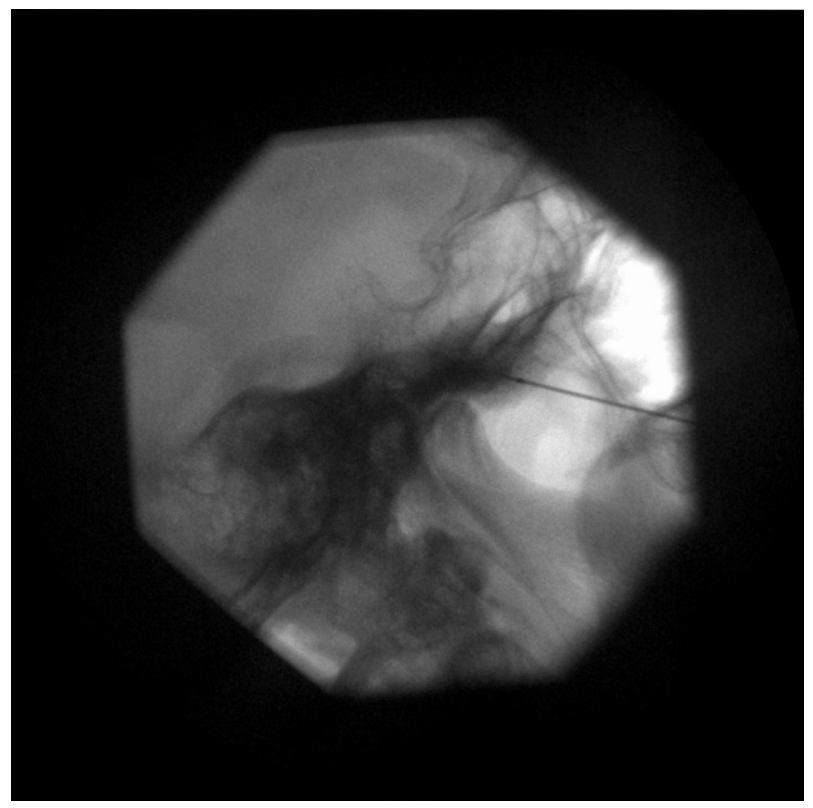

Figure $\mathbf{2}$ Lateral fluoroscopic view showing needle tip at entrance of foramen ovale. or blood. Injecting $0.5 \mathrm{~mL}$ contrast dye helps to confirm that the needle has not penetrated the dura. ${ }^{28,29}$

Test stimulation is mandatory before RF lesioning. The mandibular nerve lies in the lateral portion of the foramen ovale. If the nerve is stimulated at $2 \mathrm{~Hz}$ between 0.1 and $1.5 \mathrm{~Hz}$, muscle contraction of the lower jaw may be seen. This confirms that the needle has passed through the foramen ovale and the tip is lying on the trigeminal roots. Next, paresthesia in the concordant trigeminal distribution of the patient's usual symptoms (V1, V2, or V3 divisions) at $50 \mathrm{~Hz}$, $1 \mathrm{msec}$ pulse duration should be reproducible at $0.1-0.5 \mathrm{~V} .^{28,29}$ If paresthesia is only obtained above $0.5 \mathrm{~V}$ stimulation, the needle should be redirected to get the same response at a lower voltage. After appropriate stimulation parameters have been achieved, $0.5 \mathrm{~mL}$ of $0.25 \%$ bupivacaine with $40 \mathrm{mg}$ of triamcinolone should be injected. After waiting for at least $30 \mathrm{sec}$, RF lesioning at $60^{\circ} \mathrm{C}$ is carried out for $60 \mathrm{sec}$. The needle can be repositioned to repeat RF lesioning if more than one branch of the trigeminal nerve is involved.

Pulsed RF (PRF) is a nondestructive method of delivering RF energy to the trigeminal ganglion. In contrast to conventional RF described above, short bursts of RF current at $42^{\circ} \mathrm{C}$ are generated with long pauses between bursts to allow heat to dissipate in the target tissue. ${ }^{30}$ Thermal lesions are not produced by PRF, but recent evidence suggests that microscopic damage to axonal microfilaments and microtubules can occur, with greater changes seen in $\mathrm{C}$ fibers than A- $\beta$ or A- $\delta$ fibers. ${ }^{31}$ However, a recent randomized controlled trial comparing conventional RF with PRF showed that PRF was not effective in reducing pain in patients with TN. ${ }^{32}$ Therefore, PRF cannot be recommended as the standard therapy for rhizolysis of the trigeminal nerve.

\section{Complications}

In a large-scale, long-term follow-up of 1600 patients who had received percutaneous RF rhizotomy of the trigeminal ganglion, complications reported include diminished corneal reflex $(5.7 \%)$, masseter weakness and paralysis $(4.1 \%)$, dysesthesia ( $1 \%)$, anesthesia dolorosa $(0.8 \%)$, keratitis $(0.6 \%)$, and transient paralysis of cranial nerves III and VI $(0.8 \%)$. Permanent cranial nerve VI palsy was observed in two patients, CSF leakage in two, carotid-cavernous fistula in one, and aseptic meningitis in one. ${ }^{33}$

\section{Efficacy}

After percutaneous RF rhizotomy, initial pain relief can be achieved in $98 \%$ of patients, as high as that obtained with MVD. ${ }^{28}$ Among the various interventional pain 
therapies, RF rhizotomy offers the highest rate of complete pain relief. ${ }^{34}$ Although $15 \%-20 \%$ of patients may experience recurrence pain in 12 months, recurrence rate is the lowest among all the percutaneous techniques.

Long-term efficacy of RF rhizolysis is comparatively lower than that of MVD. ${ }^{35}$ It can be repeated in the same patient if required. In addition, it is a viable option for poor surgical risk patients or for elderly patients who are not fit for MVD because of lower morbidity and mortality rates associated with RF rhizolysis.

\section{Conclusion}

It is important to rule out secondary causes of TN, especially in young patients or patients with bilateral symptoms suggestive of multiple sclerosis. MRI scans should be obtained to help detect the presence of vascular compression of the trigeminal nerve. Medical therapy remains first line in the treatment of TN, and drugs such as carbamazepine and oxcarbazepine can be used. Surgery and interventional pain treatment can be considered in patients who have persistent pain despite drug therapy or who are unable to tolerate adverse effects of drugs.

\section{Disclosure}

The authors report no conflicts of interest in this work.

\section{References}

1. Katusic S, Beard CM, Bergstralh E, Kurland LT. Incidence and clinical features of trigeminal neuralgia, Rochester, Minnesota, 1945-1984. Ann Neurol. 1990;27(1):89-95.

2. Tölle T, Dukes E, Sadosky A. Patient burden of trigeminal neuralgia: results from a cross-sectional survey of health state impairment and treatment patterns in six European countries. Pain Pract. 2006;6(3): $153-160$

3. Marbach JJ, Lund P. Depression, anhedonia and anxiety in temporomandibular joint and other facial pain syndromes. Pain. 1981;11(1): 73-84.

4. Love $\mathrm{S}$, Coakham HB. Trigeminal neuralgia: pathology and pathogenesis. Brain. 2001;124(Pt 12):2347-2360.

5. Nurmikko TJ, Eldridge PR. Trigeminal neuralgia-pathophysiology, diagnosis and current treatment. Br J Anaesth. 2001;87(1):117-132.

6. Devor M, Govrin-Lippmann R, Rappaport ZH. Mechanism of trigeminal neuralgia: an ultrastructural analysis of trigeminal root specimens obtained during microvascular decompression surgery. J Neurosurg. 2002;96(3):532-543.

7. Headache Classification Subcommittee of the International Headache Society. The international classification of headache disorders: 2nd edition. Cephalalgia. 2004;24 Suppl 1:9-160.

8. Burchiel KJ. A new classification for facial pain. Neurosurgery. 2005; 53(5):1164-1166.

9. Eller JL, Raslan AM, Burchiel KJ. Trigeminal neuralgia: definition and classification. Neurosurg Focus. 2005;18(5):E3.

10. Cheshire WP. Trigeminal neuralgia: For one nerve a multitude of treatments. Expert Rev Neurother. 2007;7(11):1565-1579.

11. Woolfall $\mathrm{P}$, Coulthard A. Pictorail review: trigeminal nerve: anatomy and pathology. Br J Radiol. 2001;74(881):458-467.
12. Bagheri SC, Farhidvash F, Perciaccante VJ. Diagnosis and treatment of patients with trigeminal neuralgia. J Am Dent Assoc. 2004;135(12): 1713-1717.

13. Wiffen PJ, Collins S, McQuay HJ, Carroll D, Jadad A, Moore RA. Anticonvulsant drugs for acute and chronic pain. Cochrane Database Syst Rev. 2010;1:CD001133.

14. Wiffen PJ, McQuay HJ, Moore RA. Carbamazepine for acute and chronic pain. Cochrane Database Syst Rev. 2005;3:CD005451.

15. Cruccu G, Gronseth G, Alksne J, et al; American Academy of Neurology Society; European Federation of Neurological Society. AAN-EFNS guidelines on trigeminal neuralgia management. Eur J Neurol. 2008; 15(10):1013-1028.

16. Fromm GH, Terrence CF, Chattha AS. Baclofen in the treatment of trigeminal neuralgia: double-blind study and long-term follow-up. Ann Neurol. 1984;15(3):240-244.

17. Zakrzewska JM, Chaudhry Z, Nurmikko TJ, Patton DW, Mullens EL. Lamotrigine (lamictal) in refractory trigeminal neuralgia: results from a double-blind placebo controlled crossover trial. Pain. 1997;73(2): 223-230.

18. Janetta P. Trigeminal neuralgia: treatment by microvascular decompression. In: Wilkins R, Regachary S, editors. Neurosurgery. New York, NY: McGraw-Hill; 1996:3961-3968.

19. Hai J, Li ST, Pan QG. Treatment of atypical trigeminal neuralgia with microvascular decompression. Neurol India. 2006;54(1):53-56.

20. Jannetta PJ, McLaughlin MR, Casey KF. Technique of microvascular decompression. Techinical note. Neurosurg Focus. 2005;18(5):E5.

21. Sarsam Z, Garcia-Finana M, Nurmikko TJ, Varma TR, Eldridge P. The long-term outcome of microvascular decompression for trigeminal neuralgia. Br J Neurosurg. 2010;24(1):18-25.

22. Dhople AA, Adams JR, Maggio WW, Naqvi SA, Regine WF, Kwok Y. Long-term outcomes of Gamma Knife radiosurgery for classic trigeminal neuralgia: implications of treatment and critical review of the literature. Clinical article. J Neurosurg. 2009;111(2):351-358.

23. Regis J, Metellus P, Hayashi M, Roussel P, Donnet A, Bille-Turc F. Prospective controlled trial of gamma knife surgery for essential trigeminal neuralgia. J Neurosurg. 2006;104(6):913-924.

24. Oh IH, Choi SK, Park BJ, Kim TS, Rhee BA, Lim YJ. The treatment outcome of elderly patients with idiopathic trigeminal neuralgia: microvascular decompression versus gamma knife radiosurgery. J Korean Neurosurg Soc. 2008;44(4):199-204.

25. Omeis I, Smith D, Kim S, Murali R. Percutaneous balloon compression for the treatment of recurrent trigeminal neuralgia: long-term outcome in 29 patients. Stereotact Funct Neurosurg. 2008;86(4):259-265.

26. Skirving DJ, Dan NG. A 20 -year review of percutaneous balloon compression of the trigeminal ganglion. J Neurosurg. 2001;94(6): 913-917.

27. Cappabianca P, Spaziante R, Graziussi G, Taglialatela G, Peca C, de Divitiis E. Percutaneous retrogasserian glycerol rhizolysis for treatment of trigeminal neuralgia. Technique and results in 191 patients. J Neurosurg Sci. 1995;39(1):37-45.

28. Raj PP, Lou L, Erdine S, Staats PS, Waldman SD, eds. Radiographic Imaging for Regional Anesthesia and Pain Management. Philadelphia, PA: Churchill Livingstone; 2003.

29. Taha JM, Tew JM Jr. Comparison of surgical treatments for trigeminal neuralgia: reevaluation of radiofrequency rhizotomy. Neurosurgery. 1996;38(5):865-871.

30. Erdine S, Racz GB, Noe C. Somatic blocks of the head and neck. In: Raj PP, editor. Interventional Pain Management. 2nd edition. Philadelphia, PA: Saunders-Elsevier; 2008:82-87.

31. Bogduk N. Pulsed radiofrequency. Pain Med. 2006;7(5):396-407.

32. Erdine S, Bilir A, Cosman ER, Cosman ER Jr. Ultrastructural changes in axons following exposure to pulsed radiofrequency fields. Pain Pract. 2009;9(6):407-417.

33. Erdine S, Ozyalcin NS, Cimen A, Celik M, Talu GK, Disci R. Comparison of pulsed radiofrequency with conventional radiofrequency in the treatment of idiopathic trigeminal neuralgia. Eur J Pain. 2007; 11(3):309-313. 
34. Kanpolat Y, Savas A, Bekar A, Berk C. Percutaneous controlled radiofrequency trigeminal rhizotomy for the treatment of idiopathic trigeminal neuralgia: 25-year experience with 1600 patients. Neurosurgery. 2001;48(3):524-534.

35. Lopez BC, Hamlyn PJ, Zakrzewska JM. Systematic review of ablative neurosurgical techniques for the treatment of trigeminal neuralgia. Neurosurgery. 2004;54(4):973-982.
36. Tatli M, Satici O, Kanpolat Y, Sindou M. Various surgical modalities for trigeminal neuralgia: literature study of respective long-term outcomes. Acta Neurochir (Wien). 2008;150(3):243-255.

Journal of Pain Research

\section{Publish your work in this journal}

The Journal of Pain Research is an international, peer-reviewed, open access, online journal that welcomes laboratory and clinical findings in the fields of pain research and the prevention and management of pain. Original research, reviews, symposium reports, hypothesis formation and commentaries are all considered for publication.

The manuscript management system is completely online and includes a very quick and fair peer-review system, which is all easy to use. Visit http://www.dovepress.com/testimonials.php to read real quotes from published authors. 